\title{
LACAN E A ESCRITA CHINESA: UM INCONSCIENTE ESTRUTURADO COMO ESCRITA?
}

\author{
LACAN AND CHINESE WRITING: \\ AN UNCONSCIOUS STRUCTURED AS WRITING? \\ Louis-Jean Calvet \\ Universidade de Aix-Marseille \\ Aix-en-Provence, França
}

\section{Resumo}

Tomando como ponto de partida o interesse de Lacan pela China e pela língua chinesa, o artigo discute as relaçôes entre inconsciente e escrita a partir da escrita ideogramática chinesa. Observa-se, assim, à luz do diálogo de Lacan com os linguistas (Saussure, Benveniste), a tensão entre grafia e fonia nos pictogramas chineses, analisada também a partir de observações de psicanalistas chineses, para especular sobre a especificidade do inconsciente chinês.

\begin{abstract}
Lacan's well-known interest in Chinese culture and language is the starting point of the discussion put forth by this article: the relationship between the unconscious and writing, taking the Chinese ideogram as an example. Thus, informed by Lacan's dialogue with Linguistics (the works of Saussure and Benveniste), the tension between graphic and phonic elements can be observed. In the case of ideogrammatic language, the speculations of Chinese psychoanalysts also question the possible specificities of the Chinese unconscious.
\end{abstract}

\section{Résumé}

Prenant pour point de départ l'intérêt de Lacan pour la Chine et pour la langue chinoise, l'article discute les rapports entre l'inconscient et l'écriture à partir de l'écriture idéogrammatique chinoise. On observe ainsi, à la lumière du dialogue entre Lacan et les linguistes (Saussure, Benveniste), la tension entre graphie et phonie dans les pictogrammes chinois, analysée aussi à partir de remarques de psychanalystes chinois, pour spéculer sur la spécificité de l'inconscient chinois.

Incompetente em psicanálise tanto quanto é possível ser, cruzei, entretanto, com o pensamento de Lacan numa via que me levou a interrogar a teoria saussuriana do signo. Dois pontos, em particular, na obra de Lacan, se afastam um pouco da ortodoxia saussuriana e não poderiam deixar de interessar ao linguista: por um

Palavras-chave: Lacan; China; inconsciente; escrita; ideograma.

Keywords: Lacan; China; unconscious; writing; ideogram.

Mots-clés: Lacan; Chine: inconscient; écriture; idéogramme. 
* (FREUD, Sigmund. "Sur les sens opposés dans les mots primitifs". In: Essais de psychanalyse appliquée. Paris: Gallimard, 1933.)

* (ABEL, Carl. Über den Gegensinn der Urworte. Leipzig, 1884.)

* (BENVENISTE, Emile. "Remarques sur la fonction du langage dans la découverte freudienne". In: Problèmes de linguistique générale, tome 1, Paris: Gallimard, 1966: 81-82.)

* (Ibidem: 85-86.)

*(LACAN, Jacques. Ecrits I. Paris: Seuil, 1966: 22. Edição brasileira: Escritos. Tradução de Vera Ribeiro. Rio de Janeiro: Jorge Zahar Ed., 1998: 24.)

* (LACAN, Jacques. Le Séminaire, livre III. Paris: Seuil, 1981: 66. Edição brasileira: O Seminário, livro 3. Tradução de Aluísio Meneses. Rio de Janeiro: Jorge Zahar Ed., 1985: 66.) lado, sua relação com os enantiossemas e, por outro, com os anagramas de Saussure.

Comecemos pelos enantiossemas. Lacan certamente lera o artigo que Freud publicou em 1910, "A significação antitética das palavras primitivas", ${ }^{*}$ inspirado em Carl Abel, ${ }^{*}$ especialista em história do antigo Egito que defendia a ideia de que na origem as palavras podiam ter sentidos opostos. Era inevitável que isso lhe interessasse, e, quando lançou em 1956 a revista A psicanálise, pediu a Emile Benveniste um artigo sobre o tema. Será então "Observaçôes sobre a função da linguagem na descoberta freudiana”. Mas Benveniste não escreveu o artigo que Lacan esperava. Ele critica Abel, mostrando que as palavras por eles aproximadas não tinham a mesma etimologia, embora o problema não fosse diacrônico, mas sincrônico (a questão era "um significante pode ter significados diferentes ou opostos num dado momento?", e não "duas raízes podem convergir para a mesma forma?”). Opõe-se igualmente à leitura que Freud fazia de Abel, concluindo a um só tempo que "por aí se esvai a possibilidade de uma homologia entre o procedimento do sonho e o das 'línguas primitivas", * e que, "diferentemente do signo linguístico, esses significantes múltiplos e esse significado único estão constantemente ligados por uma relação de 'motivação'”.*

Lacan retomará essa questão em "O seminário sobre $A$ carta roubada". Utilizando duas vezes numa curta frase o verbo dépister em dois sentidos opostos ("Dépistons donc sa foulée là où elle nous dépiste" ["Descubramos, pois, sua pista onde ela nos despista"]), acrescenta numa nota de rodapé:

Gostaríamos de recolocar ao sr. Benveniste a questão do sentido antinômico de certas palavras, primitivas ou não [...]. Pois parecenos que essa questão permanece intacta, destacando em seu rigor a instância do significante. Bloch e Von Wartburg datam de 1875 o aparecimento da significação do verbo (dépister) no segundo emprego que dele fazemos em nossa frase.*

No que tange ao segundo ponto, os anagramas, Lacan primeiramente em seu seminário de 1955-56, levantou dúvidas quanto à linearidade da linguagem, falando antes de um conjunto de várias linhas de uma pauta [portée]: "Mas não é de todo exato que seja uma simples linha, é mais provavelmente um conjunto de várias linhas, uma ninhada [portée]. É nesse diacronismo que se instala o discurso".* 
Depois, em "A instância da letra no inconsciente", em 1857, ele refina sua metáfora: "Mas basta escutar a poesia, o que sem dúvida aconteceu com F. de Saussure, para que nela se faça ouvir uma polifonia e para que todo discurso revele alinhar-se nas diversas pautas [portées] de uma partitura".*

Finalmente, em 1966, quando a "Instância da letra" é publicada nos Escritos I, Lacan acrescenta uma nota, vendo na obra de Starobinski, que acabara de ler, a confirmação de sua ideia de pauta: "A publicação, feita por Jean Starobinski [...] das notas deixadas por Ferdinand de Saussure sobre os anagramas e seu uso hipogramático [...] dá-nos a certeza que nos faltava nessa ocasião".*

Isso, todo leitor de Lacan sabe ou pode saber: o psicanalista considerava que não havia linearidade, mas pluralidade de linhas, e disso via uma prova nos anagramas saussurianos. As palavras anagrama ou hipograma suscitam, entretanto, problema, visto que, por sua própria etimologia, remetem à letra, isto é, a um significante gráfico, enquanto Saussure parecia antes se interessar pelos sons. Paul Zumthor abordou essa questão partindo da seguinte observação: "Ao reler, há alguns meses, a canção de Bernart de Ventadorn Be mian perdut [...], pareceu-me que transparecia sob as frases e de forma minimamente diferente dos paragramas saussurianos a palavra AMOR várias vezes repetida."*

Em seguida, faz uma análise da frequência dos fonemas (e não das letras) em alguns textos de trovadores, e embora utilize na citação acima e em seu título o termo "paragrama", vai lentamente deslizar para outra palavra, "hipofone". A diferença é importante. Com efeito, é apenas em relação às letras do alfabeto que "Lacan", por exemplo, é o anagrama de "canal", mas se nos ativermos somente aos sons, transcrevendo seu nome como "lacã”, ele só se prestaria a diversas combinaçôes fônicas (e não mais gráficas) como "canla", "calan", "aclan"... Ora, essa ambiguidade das relaçōes entre significantes gráficos e fônicos que faz com que o an de "Lacan" constitua um único som (ã) com duas letras não se coloca (ou não se coloca da mesma maneira) para a escrita chinesa, como veremos.

Abordemos, agora, um detalhe da biografia de Lacan que está na origem deste artigo. Em abril de 1974, uma delegação da revista Tel Quel percorreu a China. Foi Maria-Antonieta Macciochi quem sugeriu aos chineses esse convite e Philippe Sollers quem propôs a lista dos membros da delegação: Roland Barthes, Julia Kristeva, Jean Wahl, Marcellin Pleynet e Jacques Lacan. Este explicou que
* (LACAN, Jacques. Ecrits I. Paris: Seuil, 1966: 503. Edição brasileira: Escritos. Tradução de Vera Ribeiro. Rio de Janeiro: Jorge Zahar Ed., 1998: 507.)

* (LACAN, Jacques. Ecrits I. Paris: Seuil, 1966: 503. Edição brasileira: Escritos. Tradução de Vera Ribeiro. Rio de Janeiro: Jorge Zahar Ed., 1998: 506.)

* (ZUMTHOR, Paul. “Des paragrammes chez les troubadours?". In: Langue, texte, énigme. Paris: Seuil, 1975: 58.) 
* (KRISTEVA, Julia. Les samouraïs. Paris: Fayard, 1990: 202-203.)

* (ROUDINESCO, Elisabeth. Histoire de la psychanalyse en France, tome 2. Paris: Fayard, 1994: 549.)

* (DATONG, Huo. "L'inconscient est structuré commel'écriture chinoise". Disponível em: <http://www. lacanchine.com/Ch_C_ Huolnc_Txt.html>.) havia estudado chinês durante a guerra, que retomaria seus estudos e que iria de bom grado explorar o inconsciente dos chineses, que, segundo afirma, não é estruturado como uma linguagem mas como uma escrita. Julia Kristeva, num romance à clef transparente, narra, assim, a cena:

Quanto aos chineses, é evidente que eles têm inconsciente, forçosamente, mas ele é estruturado de outra maneira, não como uma linguagem mas como uma escrita, e a diferença é capital. Mais ainda: os chineses não têm nada a ver com os japoneses. Por causa do tao. É preciso ouvi-los de perto!*

Entretanto, Lacan declinará no último momento. Talvez porque quisesse ser o responsável pela delegação francesa e Phillipe Sollers não estivesse disposto a ceder-lhe o lugar? Foi a versão que me foi contada por Sollers, ${ }^{1}$ que precisou, contudo, que foram os chineses que o escolheram. Ou seria porque sua namorada, para quem ele conseguira um visto, decidiu não ir à China? Essa é a versão de Elisabeth Roudinesco: "Três dias mais tarde, Sua Majestade foi à Embaixada e desistiu da viagem: sua namorada não quis ir. Não havia Oriente vermelho para a doutora Lacan".*

Foi também a versão de Sollers, num outro romance à clef, Mulheres. Lacan tornou-se Fals, a viagem à China tornou-se uma viagem à Índia, e foi Armande, "sua amante noำ", que fez com que a viagem desandasse. ${ }^{2}$

Seja como for, permanece a ideia de que o inconsciente chinês seja estruturado como uma escrita. Um quarto de século mais tarde, no início do ano 2000, Huo Datong, psicanalista chinês formado na França, publicou um artigo intitulado "O inconsciente é estruturado como a escrita chinesa”. * Não faz nenhuma alusão ao que precede, precisando apenas que toma como ponto de partida a frase de Lacan segundo a qual "o inconsciente é estruturado como uma linguagem", e que Lacan pensava provavelmente em uma língua como o francês, enquanto o chinês apresenta uma grande diferença em relação a ela: as palavras ali seriam ambíguas. E para ele, é a escrita que desfaz essa ambiguidade:

É pela escrita, sobretudo pelos ideofonogramas, dentre os quais uma parte representa o som e a outra a figura, que se resolve a grande

\footnotetext{
${ }^{1}$ Comunicação pessoal.

${ }^{2}$ Femmes, Paris: Gallimard, 1983, citado aqui na edição Folio, 2012: 97-99. Quando perguntei a Sollers sobre a ausência de Lacan na China, ele me respondeu: "Está em Mulheres".
} 
confusão que resulta do fato de que uma única sílaba representa várias ou mesmo algumas dezenas de palavras.*

A partir desse postulado, discutível, como veremos, Huo Datong explica que "a ruptura entre a figura do sinograma e o som significa a ruptura que ocorre entre a ordem imaginária e a ordem do simbolismo":

Queremos continuar aqui a discutir a estrutura dessa categoria do ideofonograma. Qualquer ideofonograma dessa categoria, o de 妈 ( $m a$, mãe, ou mais precisamente, ma de mamãe), por exemplo, se compõe de dois pictogramas. À esquerda, 女, o pictograma de mulher, e à direita, 马, o pictograma de cavalo. Como já indicamos acima, cada um desses dois pictogramas compreende igualmente três elementos: a figura, o som e o significado, mas, queremos deixar agora o elemento de significado de lado para facilitar nossa discussão [...].

Podemos observar que o pictograma de mulher no ideofonograma de mãe não se pronuncia, ou seja, seu elemento fonético foi recalcado ou apagado [...]

Podemos, portanto, dizer que a construção do ideofonograma de mãe é condicionada pelo recalque recíproco que se produz entre esses dois componentes, o de mãe e o de cavalo. Agora, o pictograma de mulher se tornou um caractere mudo por representar apenas a figura, e não o som; o de cavalo, um caractere cego por representar apenas o som, e não a figura.*

E, após longos desenvolvimentos, chega à conclusão de que:

Considerando uma ideia chinesa segundo a qual o que se viu é cheio e o que se ouviu é vazio, a prática clínica da psicanálise enquanto atividade de falar-escutar deve ser considerada como uma prática de conduzir o cheio pelo vazio.*

Como disse acima, o ponto de partida de Huo Datong, de forma surpreendente, uma vez que o chinês é sua língua materna (é verdade, porém, que ele não é linguista), me parece discutível: dizer, como ele o faz, que as "palavras" chinesas são ambíguas e que essa ambiguidade é desfeita pela escrita consiste, com efeito, em fazer abstração dos tons. O exemplo que ele dá, o do caractere significando a "mãe" e composto de dois caracteres, o da mãe e o do cavalo, não funciona no sentido que ele atribui, posto que, como veremos, a "mãe" e o "cavalo" não são pronunciados da mesma maneira, não são pronunciados com o mesmo tom. Voltaremos a isso, mas essa precisão é importante para compreender o que se segue. Limitemo-nos, pois, por enquanto, a seu artigo, ao qual res- 
* a(LEW, René. "Commentaire du texte de Huo Datung intitulé «L'inconscient est structuré comme l'écriture chinoise»". Disponível em: $<$ http://www.lacanchine. com/Ch_C_Huolnc_Lew. $\mathrm{html}>$.)

* (ABIBON, Richard. "Réponse à Huo Datong". In: Psychologie Clinique, jul. 2003, n. 15. Paris: L'Harmattan, 2003.)

* (MASSAT, Guy. "Huo Datong: La révolution psychanalytique chinoise". Disponível em: <http://www.lacanchine.com/Massat_01. html>.)

* (LEW, René, op. cit.)

* (Idem.)

* (ABIBON, Richard, op. cit.) ponderam, entre 2002 e 2008, ao menos, três psicanalistas franceses: René Lew,* Richard Abibon* e Guy Massat.*

O primeiro, René Lew, após ter feito a precisão de que não conhecia o chinês, expressa sua distância em relação às posiçôes defendidas por Huo: "Discordo de Huo Datong quando efetua a forçação de enquadrar a tríade significado, fonética, sinograma naquela de Lacan, clássica hoje, respectivamente o real, o simbólico e o imaginário".*

Depois, menciona o exemplo da "mãe":

Huo Datong dá o exemplo do ideograma que significa "mãe" e se pronuncia ma (um ma que Huo Datong refere também a "mamãe"). Deixa de lado o significado para considerar apenas a dualidade figura-som. O ideograma $m a$ associa esses dois outros que significam cada um separadamente "mulher" e "cavalo". Mas o elemento fônico "mulher" do pictograma não é pronunciado. Dele subsiste apenas a figura ideográfica e inversamente o elemento "cavalo" só desempenha um papel fonético, sem mais valor representativo ou figuração referida a um cavalo. Este pictograma só implica o som ma. Huo Datong fala aí de um duplo "recalque" (5.1), o caractere "mulher" se tornou mudo e o "cavalo" se tornou não representativo. Para Huo Datong isso associa imaginário (mulher) e simbólico (cavalo).*

Richard Abibon, por sua vez, declara que estuda chinês e sabe que Lacan conhecia essa língua. Comenta longamente a definição saussuriana do significante e do significado, depois se refere ao interesse de Freud pelos hieróglifos egípcios:

É preciso lembrar que o interesse de Freud pelos hieróglifos egípcios teve consequências na descoberta da psicanálise. Tanto quanto me é dado a saber, estes funcionam da mesma maneira que os caracteres chineses. Se o inconsciente é estruturado como um caractere chinês, a própria psicanálise, em sua origem, era muita mais chinesa do que parece, mas sem sabê-lo.*

Em seguida, evoca também o exemplo do caractere designando a "mãe":

O exemplo dado por Huo Datong do significado "mamãe" e, particularmente falando, o som "ma" é tomado de empréstimo a “马” (cavalo), mas contíguo ao caractere “女” (nü), “mulher”, ele significa "mamãe", que se pronuncia "ma”: 妈.

Embora falando dialetos muito diferentes, todos os chineses podem ler os mesmos caracteres. Cada leitor, no momento da leitura, "ouve" o caractere em seu próprio dialeto. Da mesma forma, ele pode ser compreendido por outro chinês que não fale o mesmo dialeto, pelo viés da escrita. 
Enfim, como as homofonias são muito numerosas em chinês, como observa Huo Datong, a escrita no ar ou na palma da mão, esboço de um caractere, permite dissipar o equívoco quando ocorre.

O caractere chinês é mesmo, portanto, representação de coisa, mas difere da representação de coisa freudiana por se comunicar: é uma letra legível. A ligação com a representação de palavra que opera a passagem ao consciente se faz na língua daquele que lê, mesmo que ela seja diferente da língua daquele que escreve.

Nesse sentido, a afirmação de Huo Datong: "o inconsciente é estruturado como o caractere chinês" é perfeitamente válida. $\mathrm{O}$ estudo linguístico do caractere chinês o propõe como uma metáfora da estrutura do inconsciente. $\mathrm{O}$ empréstimo, pelo qual um som se encontra deslocado de uma letra a outra, dá uma boa imagem do que Freud chamava de deslocamento, que é um dos meios de que se serve o recalque.*

O caractere chinês e seus modos de composição poderiam, portanto, ser tomados como uma metáfora da estrutura do inconsciente. Depois, provavelmente para mostrar que conhece perfeitamente o chinês, Abibon propõe dois enigmas, um em francês e outro em chinês:

Vou agora dar um exemplo de jogo entre o significante e a letra, cuja estrutura é quase semelhante em chinês e em francês.

Em francês, primeiramente:

Elle est au fond du jardin, elle se montre au début de la nuit, mais on ne la voit qu'une fois par an.

Quem é? A letra "n", é claro!

Por esse chiste, retiramos a letra "n" de sua função de representação do som (representação de palavra) para remetê-la, como no sonho, à sua pura função de letra (representação de coisa). Quando a adivinhação é proposta oralmente, só se pode resolvê-la saindo do oral e fazendo referência ao escrito.

Em chinês:

你没有他有

天没有地有

(Ni mei you, ta you,

tian mei you, di you)

Você não tem, ele tem;

o céu não tem, a terra tem.

Quem é? a letra “也” (ye) é claro!”*

Mas, ao fazê-lo, ele comete um erro de análise, pois o que chama de "letra" 也 não é evidentemente uma letra, mas um caractere que se pode utilizar isoladamente, que se pronuncia efetivamente ye em mandarim, e que aparece aqui nos dois signos com- 
postos (他 e 地), assim como o caractere significando a mãe é composto dos caracteres significando a mulher e o cavalo. Entretanto, Abibon retoma essa associação do cavalo e da mãe (e devo aqui me antecipar sobre o que explicarei abaixo, fazendo a precisão de que o cavalo tem no caractere composto 媽 uma função fonética e a mulher uma função semântica):

A pronúncia de "ma" com a intenção de significar "cavalo" se faz no triskel onde Lacan colocara o gozo fálico. É verdade que esse animal é posto frequentemente entre as pernas e que assim multiplica a potência de deslocamento do cavaleiro. Um dos anéis desse triskel contribui para outro triskel, o da enunciação correspondente a "mamãe". O outro se origina no triskel do significante de uma falta no Outro (onde Lacan colocara o gozo do Outro, G (A barrado) o que considero aqui como equivalente; é evidente que isso é discutível): não há fiador da verdade, e na enunciação a báscula de um significado a outro é sempre possível. O $3^{\circ}$ anel desse triskel se origina acompanhando o objeto $a$, impronunciável, exceto sob essa forma metafórica que termina ao longo da significação recalcada em zona vermelha.*

O terceiro participante nesse debate, Guy Massat, considera, a seu turno, que o texto de Huo Datong constitui uma verdadeira revolução psicanalítica. Ele se aferra ao exemplo do caractere significante de "mãe" (mas é verdade que há aí um tema que não pode deixar de interpelar um psicanalista) e cavalga alegremente o "cavalo", interpretando suas relações de uma forma que faz sonhar. A longa passagem que se segue dispensa comentários:

Tomemos a palavra "mamãe". Ela é composta em chinês pelo ideograma mulher e pelo ideograma cavalo. Por que a palavra "mamãe" não é representada pelo ideograma "mulher" e pelo ideograma "criança"? Não seria mais conforme à realidade? Uma mulher mais uma criança não evocam uma mamãe? Evidentemente, mas nesse caso seria negar a linguagem inconsciente como o fazem as outras línguas. "Mulher mais cavalo" vai articular jogos de recalques de imagens por sons e de sons por imagens. Além disso, "mulher mais cavalo" evoca imediatamente para os psicanalistas "o caso Dora", no qual a mãe é provida de falo, ou ainda o caso do "Pequeno Hans", para quem a palavra $P f e r d$,que significa "cavalo" em alemão, ressoa com Freud (ver As Cinco liçôes de Psicanálise de Freud). Mulher mais cavalo evoca ainda a cena primitiva na qual a criança presencia a relação sexual de seus pais. A mãe está embaixo, como o cavalo, e o pai em cima, como o cavaleiro. Se nos reportarmos à linguagem, o significado, o sentido, representado pelo "pai" se encontra em cima, e a palavra, "mãe", o significante, embaixo. Somos levados pelas palavras como éramos levados por nossa mãe. Vocês conhecem a 
história daquele homem, levado pelo galope de seu cavalo, a quem perguntam: aonde você vai? E ele responde: Não sei, pergunte ao cavalo! Pode-se ainda evocar a peça de Peter Shaffer que está em cena agora, Equus, na qual um psiquiatra é confrontado a um adolescente que furou os olhos de seu cavalo preferido, etc. A mulher a cavalo, a mulher cavalo, a mulher centauro, a mulher sem defeitos, a mulher não teria defeitos? ${ }^{3}$ A mãe tem sempre razão? Foi Poseidon, o Deus do mar, ${ }^{4}$ que ofereceu aos atenienses o cavalo que não quiseram, tendo-lhe preferido a oliveira. O som $[m a]$, em chinês, pode tanto significar a "mãe" quanto "o cavalo", "o cânhamo", kannabis em grego, (o que talvez explique que aqueles que fumam busquem reencontrar a beatitude do bebê nos braços da mãe), o som [ma] quer dizer ainda "maldizer" ou "jogar um feitiço". E isso não é exaustivo. O sentido dos sons se metamorfoseia sem cessar.*

* (MASSAT, Guy, op. cit.)

Voltemos agora à fórmula de Lacan referida por Kristeva, segundo a qual o inconsciente dos chineses seria estruturado como uma escrita, e notemos que essa fórmula é muito diferente daquela de Huo Datong, para quem o inconsciente seria estruturado como a escrita chinesa. No primeiro caso há um referente particular (o inconsciente dos chineses), no segundo, um referente mais amplo (o inconsciente), mas também no primeiro caso há um referente vago (uma escrita), e no segundo um referente mais preciso (a escrita chinesa). Afinal, o inconsciente ou o inconsciente dos chineses? Uma escrita ou a escrita chinesa?

É evidente que não sei precisamente o que disse Lacan nem exatamente em que ele pensava, mas tenho algumas ideias que gostaria modestamente de ilustrar, ainda que seja para abrir o debate. Notemos primeiramente que Lacan realmente estudou chinês no curso universitário de Línguas Orientais, ao longo de três anos (1942-43, 1943-44 e 1944-45), quando tinha mais de quarenta anos, e sabia, pois, perfeitamente o que vou explicar agora sobre a escrita chinesa, que é, originalmente, pictográfica, isto é, ela representa graficamente o que designa. Por exemplo, esse caractere 木 representa uma árvore, e em suas primeiras aparições sobre ossos (omoplatas de bois, carapaças de tartarugas) gravados distinguem-se raízes, um tronco e galhos. Mas os pictogramas perdem sempre a motivação (também é o caso dos cuneiformes sumérios), tornam-se

\footnotetext{
${ }^{3}$ Em francês, "La femme à cheval, la femme cheval, la femme centaure, la femme sans tort, la femme est-elle sans tort?" joga com a homofonia entre "centaure" e "sans tort". (N. da T.)

${ }^{4}$ Em francês, "Dieu de la mer" ("mar"), este sendo homófono de mãe ("mère"). (N. da T.)
} 
abstratos, e, se um leitor do chinês sabe que 馬 remete ao cavalo, só uma análise etimológica (trata-se aqui de etimologia gráfica) nos lembra que se distinguem nesse caractere a crina, as ancas, as quatro patas e o rabo do animal. Acrescentemos a isso que nem 木 nem 馬 5 nos indicam como se deve pronunciá-los, ou se preferirmos, como se dizem "árvore" e "cavalo" nas línguas chinesas. "As línguas", pois não há uma língua chinesa, mas várias, sete línguas diferentes (embora, na China, persista-se em geral em chamar seis delas de "dialetos") que utilizam o mesmo sistema gráfico. As notações que darei abaixo são as da pronúncia na língua oficial, o pu tong hua, que é comumente chamado no Ocidente de mandarim.

Esses caracteres simples têm um número limitado e são combinados segundo dois princípios distintos, dentre os quais o primeiro joga com o sentido e com o som, e o segundo apenas com o sentido. Assim, o cavalo 馬é pronunciado em mandarim $m a$, com o terceiro tom. Muitos caracteres compostos vão jogar com o fato de que outras palavras são pronunciadas $m a$, com tons diferentes. Assim, a mãe, e o caractere que a designa, 媽, pode se decodificar da forma seguinte: ela é pronunciada quase como o cavalo (quase no mesmo tom), e isso tem uma relação com a mulher (a primeira parte do caractere: 女), portanto, é a "mãe", ma com o primeiro tom. O mesmo vale para 罵, onde se veem acima do cavalo duas bocas: isso se relaciona com a comunicação e se pronuncia quase como o cavalo: é "injuriar", ma, no quarto tom. Mas há outra forma de compor os caracteres que em nada utiliza seu fonetismo. Consideremos esses três caracteres, 火, 禾 e 心. O primeiro designa o fogo e é pronunciado em mandarim huo, o segundo designa o cereal e se pronuncia hè, o terceiro designa o coração e é pronunciado xin. Ao mesmo tempo, em composição, 心 indica que o caractere composto diz respeito aos sentimentos. Tomando os dois caracteres dessa série, 火禾心, podemos compor o caractere 秋, que se pronuncia qiu e significa "outono". Acrescentando o coração, obtemos愁, que se pronuncia chou e significa "melancolia”. Uma abordagem em termos de etimologia gráfica poderia nos dizer que 秋 remete à estação ao longo da qual os cereais têm a cor do fogo, ou à estação ao longo da qual os cereais são queimados. Quanto a 愁, “melancolia”, podemos interpretá-lo como "sentimento de

\footnotetext{
${ }^{5}$ Notemos que Huo Datong utiliza os caracteres simplificados da China comunista e que eu utilizo os caracteres clássicos, mas isso não muda em nada meu raciocínio.
} 
outono", ou "sentimento da estação ao longo da qual os cereais são queimados" etc. Mas um leitor chinês não faz necessariamente essa análise, ele sabe que 愁 significa “melancolia" e que se pronuncia chou, e isso é tudo. Essas composições semânticas podem, contudo, para o analista (não falo aqui do psicanalista, não ainda, mas do linguista), conotar indicaçôes sobre a cultura ou a ideologia chinesa. Por exemplo, a "família" se escreve家e se diz (exclama) ${ }^{6}$ jia. Mas esse caractere é composto por um teto sob o qual se encontra um porco: a família era, portanto, concebida como a associação de uma casa e de um porco. Mais uma vez, não é necessário decompor esse caractere para saber que 家 remete a "família" que se pronuncia jia, mas...

Mas os exemplos seguintes vão nos mostrar que nesse nível das diferentes partes dos caracteres compostos há, apesar de tudo, um discurso. Voltemos ao caractere女, “mulher”, cuja pronúncia é pouco importante, mas cuja etimologia gráfica nos mostra que no estado pictográfico ele representava uma mulher agachada, trabalhando, ou em posição de submissão. Eles são encontrados em diferentes caracteres compostos:

- 安 designando a paz, a tranquilidade, e representando uma mulher sob um telhado (a mulher no lar?).

- 好 designando o que é bom e representando uma mulher e uma criança.

- 奴 designando o escravo e representando uma mulher sob a dominação de uma mão.

- 怒designando a cólera, concebida, como indicado pelo caractere心 acrescentado ao precedente como um sentimento de escravo.

- 嫁 significando "desposar um homem" e representando uma mulher e uma família.

- 妻 significando "esposa" e representando uma vassoura e uma mulher.

Podemos, portanto, ver nessa série em que todos os elementos têm em comum o fato de conter o caractere 女, “mulher”, uma imagem do estatuto da mulher na sociedade chinesa na época em que essa escrita se estabilizou, há mais de dois mil anos. Mas podemos ao mesmo tempo nos perguntar se, por exemplo, frente ao nome da praça central de Pequim, 天安門 (tian an men, "portal da paz celeste”), um leitor chinês percebe confusamente em 安, “paz”, a

${ }^{6}$ Em francês, "Par exemple la 'famille' sécrit 家 et se dit (s'écrie??);" sécrit e sécrie são homófonos. (N. da T.) 
mulher no lar ou a mulher sob um telhado. Vemos aqui uma continuidade, uma linearidade (a sequência 天安門) e o que chamarei de "profundidade" do segundo caractere (os dois caracteres simples de que é composto esse caractere complexo e o que eles podem conotar: a paz igual à mulher no lar). $\mathrm{O}$ mesmo vale, aliás, para o caractere significando "melancolia" que evocamos acima: ele se insere numa linearidade, precedido e seguido de outros caracteres, mas composto por três caracteres, presta-se também a uma leitura vertical, ou "em profundidade". E isso é verdadeiro para milhares de outros caracteres chineses. $\mathrm{O}$ que significa que os caracteres chineses colocam o problema da linearidade de uma maneira diferente. Eles se sucedem, certamente, numa ordem linear, mas quando são compostos, acrescentam ali outra dimensão, uma profundidade, um sentido suplementar. E isso, Lacan sabia perfeitamente. É evidente que se trata aqui apenas de etimologia, de etimologia gráfica, mas de etimologia. Ora, os locutores de qualquer língua ignoram em geral a etimologia. Pode-se pronunciar milhōes de vezes a palavra francesa trabalho sem saber que ela vem de uma palavra latina, tripalium, designando um instrumento de tortura formado por três estacas, e isso não impede absolutamente que ela seja utilizada de forma "adequada". Mas o caso do chinês é diferente. As palavras têm evidentemente uma etimologia fônica que os locutores ignoram em sua maioria, mas os caracteres têm, além disso, uma etimologia gráfica que, conscientemente ou não, fala aos olhos. E voltando à fórmula segundo a qual o inconsciente dos chineses é estruturado como uma escrita, há nela um ponto de partida que merece ser explorado se quisermos tentar compreender o que Lacan queria dizer.

Dispomos aqui de um ponto de vista interessante, o de Elisabeth Roudinesco, que no início dos anos 1970 viu Lacan, ao voltar de uma viagem ao Japão, comentar a obra de Barthes, $O$ império dos signos. Ele procurava então "reafirmar a ideia da primazia do significante sobre a letra", escreve ela, e não ver na "coisa japonesa" um "outro invertido". Roudinesco lembra que ele estudou o chinês, que era atraído pelo Oriente, e que "procurava sempre resolver o mesmo enigma mallarmeano: como 'escrever', isto é, 'forma-

*(ROUDINESCO, Elisabeth. Lacan, envers et contre tout. Paris: Seuil, 2011: 87-88.) lizar' a tópica do real, simbólico e imaginário". Continuemos no eixo biográfico. Antes do episódio da viagem mal sucedida para a China, no início dos anos 1970, François Cheng encontrou regularmente Jacques Lacan a pedido deste, que desejava trabalhar com 
ele textos de Laozi, Mencius e Shitao, e ele contou essas sessões.* Cheng salienta, sobretudo, o interesse do psicanalista pelo taoísmo, o confucionismo ou a pintura, mas uma passagem de seu texto me parece suscitar atenção:

Lacan gostou dos ideogramas - por sua forma e por sua maneira engenhosa de sugerir o sentido - assim como da caligrafia [...]. Mas o que fascinava Lacan eram antes esses signos escritos enquanto sistema. Um sistema que está a serviço da palavra, embora mantendo uma distância em relação a ela. Como cada ideograma forma uma unidade autônoma e invariável, seu poder significante só se dilui pouco na cadeia. Assim, embora capaz de transcrever fielmente a palavra, o sistema pode também, por todo um processo de elipse voluntária e de combinação livre, engendrar em seu seio um sinal aberto, isso, sobretudo, na linguagem poética, onde no interior de um signo e entre os signos o Vazio-mediano joga pulverizando a ascendência da linearidade unidimensional.*

Cheng encerrará esses encontros com Lacan em 1974 para se dedicar à redação de uma obra que será publicada em 1977, A escrita poética chinesa, ${ }^{*}$ e podemos nos perguntar se nesse livro não há ecos de suas trocas com Lacan. O aspecto subliminar é, com efeito, evocado por ele com muita frequência, de uma forma que faz muito mais referência à grafia do que à fonia. Ele dá, assim, o exemplo de um verso de Wang Wei, composto por esses cinco caracteres，木末芙蓉花, que ele traduz por “na ponta dos galhos flores de hibisco" e, sem indicar de que forma esses caracteres são pronunciados, analisa essa sequência do ponto de vista de seu aspecto visual, evidenciando particularmente a presença subliminar e obsedante do homem (人).* De fato, o signo do homem só aparece realmente no quinto caractere, e nos outros se pode ver o homem nas raízes de uma árvore, em particular nos três primeiros caracteres. Mas sua ideia de uma pulverização da "ascendência da linearidade unidimensional" deve ser mensurada com cuidado, quando lembramos que vinte anos antes, em seu período estruturalista, Lacan se inspirava em Saussure e em Jakobson, e que a linearidade da linguagem era central para eles. Só depois se interroga sobre essa linearidade falando das "pautas". O que significa que temos aqui dois problemas. $\mathrm{O}$ primeiro concerne às relações entre o escrito e o oral (Como isso se escreve? Como isso exclama? ${ }^{7}$ Lacan ou lacâ?). O segundo diz respeito ao que chamei de "profundidade"
* (Ver CHENG, F. "Lacan et la pensée chinoise". In: Lacan, l'écrit, l'image. Paris: Flammarion, 2000.)

* (Ibidem: 150-151.)

* (CHENG, F. L'écriture poétique chinoise. Paris: Seuil, 1977.)

* (Ibidem: 18.)

${ }^{7}$ Em francês, "Comment ça sécrit?? Comment ça sécrie?." (N. da T.) 
* (FREUD, S. "Sur les sens opposés dans les mots primitifs". In: Essais de psychanalyse appliquée. Paris: Gallimard, 1933.) do signo gráfico chinês, o que ele pode "dizer" nele mesmo, sem referência à forma pela qual é pronunciado: 妻 significa "esposa" e representa uma mulher e uma vassoura, 安 significa "paz" e representa uma mulher sob um teto, uma mulher no lar etc.

$\mathrm{O}$ inconsciente dos chineses estruturado como uma escrita e não como uma linguagem? Esse dito espirituoso, ou essa intuição, poderia talvez ter um início de explicação nas especificidades gráficas do chinês, no discurso conotado pela escrita chinesa, "um sistema que está a serviço da palavra, embora mantendo uma distância em relação a ela", um sistema no qual "como cada ideograma forma uma unidade autônoma e invariável, seu poder significante só se dilui pouco na cadeia” (F. Cheng). E o fato de que no momento em que se acenava a possibilidade de uma viagem para a China Lacan encerrava quatro anos de trabalho sobre textos chineses com o especialista dessa escrita François Cheng talvez seja um indício. Pois no cerne do debate se encontram as relações entre a grafia e a fonia, o fato de que as escritas alfabéticas remetem diretamente ao som enquanto a grafia chinesa não tem o mesmo tipo de ligação com a fonia, ou antes, com as fonias, posto que um mesmo caractere é pronunciado de diferentes formas nos diferentes chineses. Grafia/fonia: a ambiguidade de suas relações está posta, como vimos, desde os anagramas de Saussure. Praticamente na mesma época, Freud marcava seu interesse pela tese de Abel concernente "aos sentidos antitéticos nas palavras primitivas", os enantiossemas. E esse interesse estava diretamente ligado ao seu trabalho sobre o sonho e ao fato de que o mesmo elemento podia ter ali dois sentidos opostos:

O sonho não exprime jamais a alternativa "ou/ou", mas acolhe os dois termos como igualmente justificados na mesma correlação. Já salientei que "ou/ou" utilizado pela produção onírica deve ser traduzido por "e". Representações que se encontram em mútua oposição são expressas no sonho preferencialmente pelo mesmo elemento.*

Ora, se as reflexōes de Jacques Lacan sobre o significante foram com toda evidência amplamente alimentadas por Saussure e Freud (cf. o episódio do artigo pedido a Emile Benveniste, e depois sua volta ao mesmo tema dos enantiossemas no "Seminário sobre $A$ carta roubada"), é plausível que seu conhecimento do chinês tenha trazido a essas reflexões uma nova direção. Se o significante fônico é a matéria central da psicanálise, os significantes gráficos da escrita 
lhe colocavam outro problema. Com que se parece um sonho chinês? Pode-se aventar a hipótese de que Lacan supunha e queria verificar que os chineses sonhavam em caracteres.

Tradução de Márcia Atálla Pietroluongo

(Professora de Língua Francesa na UFRJ. E-mail: pietromarcia@gmail.com)

Louis-Jean Calvet é doutor em Linguística pela Sorbonne, doutor em Letras e Ciências Humanas pela Universidade de Paris V. Foi professor da Sorbonne (Universidade René Descartes) até 1999 e atualmente é professor emérito na Universidade de Aix-Marseille (antiga Universidade de Provence). Publicou mais de quarenta livros, e sua obra inclui estudos sobre Roland Barthes, Ferdinand de Saussure, sobre a canção francesa, a francofonia, a história da escrita, a diversidade linguística, as relaçóes entre língua e colonialismo. Email: louis-jean.calvet@wanadoo.fr. 